\title{
Problems of field contamination when growing energy corn as monoculture
}

\author{
Mykola Korchak, Serhii Yermakov*, Vasyl Maisus, Serhiy Oleksiyko, Vitaliy Pukas and \\ Iryna Zavadskaya
}

State Agrarian and Engineering University in Podilia, 32300 Kamianets-Podilskyi, Ukraine

\begin{abstract}
Use of corn for energy purposes has high potential. To ensure the sustainable arrival of raw materials the possibility of using it as monoculture is important. To do it is necessary to quickly release the field from plant residues. The results of the study of the state and analysis of the nature of the field weediness by leaf-stem and root residues after harvesting corn are given taking into account the possibility of further use of the field for growing energetic corn.
\end{abstract}

\section{Introduction}

Corn is one of the most common crops both in Ukraine and abroad, which has significant advantages over other cereals in terms of yield, nutrition and cost price and other economic indicators. The presence of a large number of leafy stalk mass allows us to consider it as an energy culture therefore the state's fuel and energy sector is interested in its production, since it is a high-energy raw material for the production of production of biofuels and other fuel materials.

Corn biomass is effectively used in the energy sector, the non-cereal part of corn is used in the form of solid fuel in the form of granules, briquettes and bales because it has better fuel characteristics than straw grains of corn. In addition the biomass of corn has good energy indicators relative to other types of energy carriers of plant origin which positively characterizes this raw material for use as an energy source.

A promising direction for the use of the stem mass of corn is also the production of bioethanol (from 1 ton of grain you can get up to 400 liters of ethyl alcohol). The use of the energy-based fuels in the energy market is becoming increasingly relevant since it is projected to increase production worldwide.

Given the prospects for the development of a raw material base for the production of biological fuels from corn the prerequisites for the formation of bioenergy in Ukraine are emerging.

The development and implementation of energy-efficient directions for growing corn hybrids for the use of grain and leaf-stem mass for energy needs is important in modern conditions.

\footnotetext{
* Corresponding author: $\underline{\text { ermkov@gmail.com }}$
} 
To constantly replenish the raw material base of corn it is important to ensure uninterrupted cultivation of corn in sufficient quantities. In conditions of narrowly targeted agriculture the possibility of using corn as a monoculture becomes relevant.

Monoculture corn cultivation provides a high-yield of grain per unit area, enhances soil erosion control, requires the creation of appropriate hybrids with a stable yield and resistance to pests and diseases according to the growing zone which allows to use part of the grain yield and foliage-stem mass for energy needs.

In the system of autumn tillage for maize crops in a monoculture great importance is given to the thorough grinding of crop stalk residues. That is why the study of the state of weediness of the field after harvesting the corn remains quite relevant.

Some studies of the state of weediness of the field after harvesting corn were considered by the authors earlier [1].

The existing knowledge regarding the use of plant residues of maize for energy purpose gives reason to determine the urgent tasks of research on this problem. The main ones are:

- development of a yearbook for the study of the nature of weediness of the field by plant residues of corn and methods for processing experimental data;

- development of methods for the efficient use of plant residues in energy production;

- development of field processing methods after harvesting corn;

- development and creation of appropriate agricultural machinery.

Common shortcomings in the work of research institutions conducting research on the effective use of plant residues are insufficiently comprehensive research, as well as, insufficient effectiveness of coordination of scientific work.

The main goal of scientific research the results of which are given in this article is the implementation of the first stage of classical scheme: a deep study of the processing field littered with leaf stem and root residues as elements that will later be used as biofuel.

The list of questions studies includes systematization of remains in size, mutual placement on the area and on depth; determination of dimensional characteristics.

The results obtained will be the basis for further engineering decisions for developing machine designs, selecting a technological scheme; determining technological parameters.

\section{Materials and methods}

Stubble after corn harvesting was chosen as the field littered by plant residues of thick-stem crops.

The place of energy corn in crop rotation is determined by the requirements for the structure of the soil the reserves of moisture, and nutrients in it, the degree of debris in the fields and the contamination by plant residues after harvesting it. It also takes into account the value of corn as precursor for other crops. But, when using corn as an energy crop, often becomes important to grow corn biomass on the same area, that is, when growing it as a monoculture [2-6].

The most significant factors causing interest in corn in this regard are shown in Figure 1. 


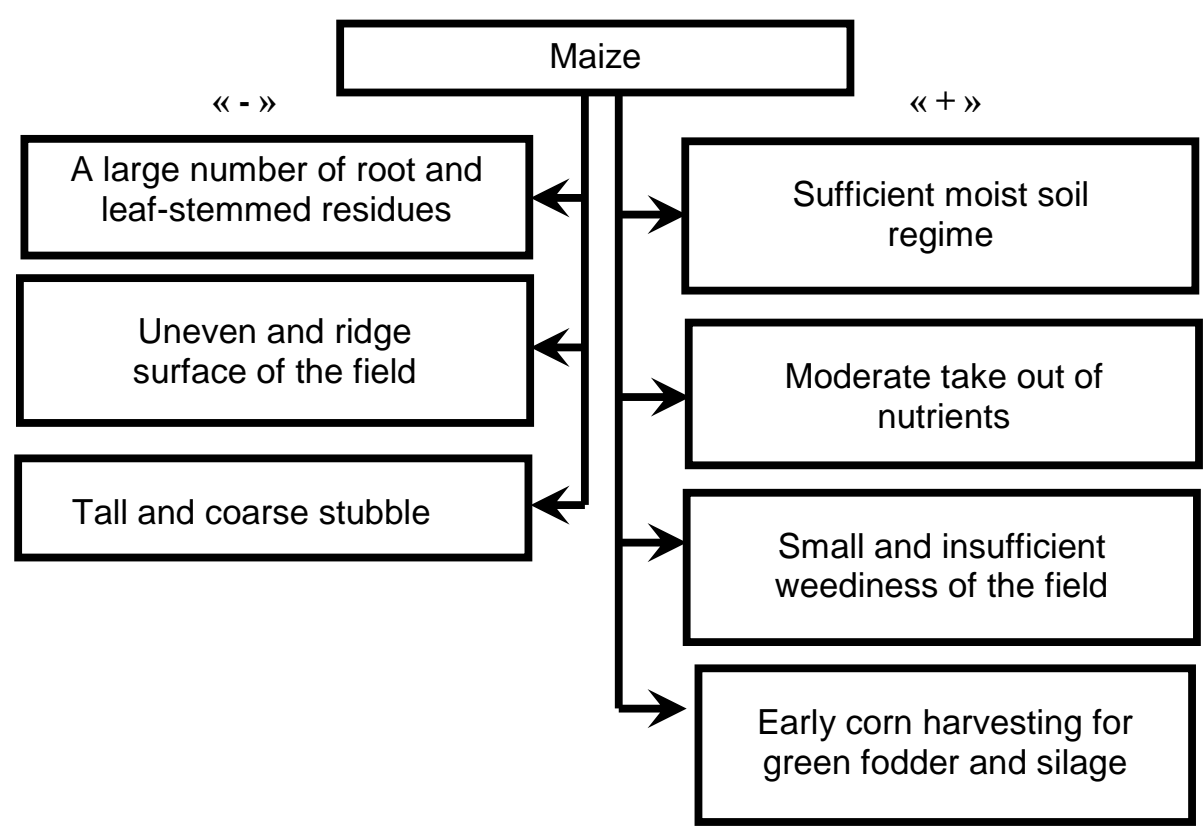

Fig. 1. Prerequisites for using corn as a precursor for other cops

It is clear from the diagram that the main arguments that prevent the effective use of the field are large number of thick-stemmed plant residues that remain after harvesting, as well as a rather uneven ridged field surface.

To find ways and means of solving this problem you should carefully examine the state of the field after corn harvesting.

The main purpose of field contamination is: a deep study of the processing object of leaf and root debris as elements that need to be crushed in time and embedded into the soil.

The list of questions studied includes:

- systematization of residues by size;

- analysis of mutual distribution in the area and in depth;

- determination of dimensional characteristics.

The analysis of quantitative characteristics the field contamination condition was carried out by the way of immediate calculation and measurement of plant residues remained on field surface designating it for experimental plots.

Valid sites for measuring there were plots with the size of $2 \mathrm{~m}$ on the length of rows and the lane width of $1,4 \mathrm{~m}$. The scheme for measuring is a diagonal one.

On the plot (Fig. 2) there were calculated:

1. Stem number placed:

- alongside of inter-rows;

- transversely;

- at an angle to the left on $10-20^{\circ}, 30-40^{\circ}, 50-60^{\circ}, 70-80^{\circ}$;

- at an angle to the right on $10-20^{\circ}, 30-40^{\circ}, 50-60^{\circ}, 70-80^{\circ}$;

- total number of stems.

2. Stems length: 
- longitudinal (as well those that were deviated to $40^{\circ}$ );

- transverse $\left(50-80^{\circ}\right)$.

Experimentaly there were determined:

1. Plant residues diameters:

- rhizomes diameters d;

- ground parts diameters d;

2. Plant residues height:

- rhizomes height (provisionally) h;

- ground parts height (provisionally) h.
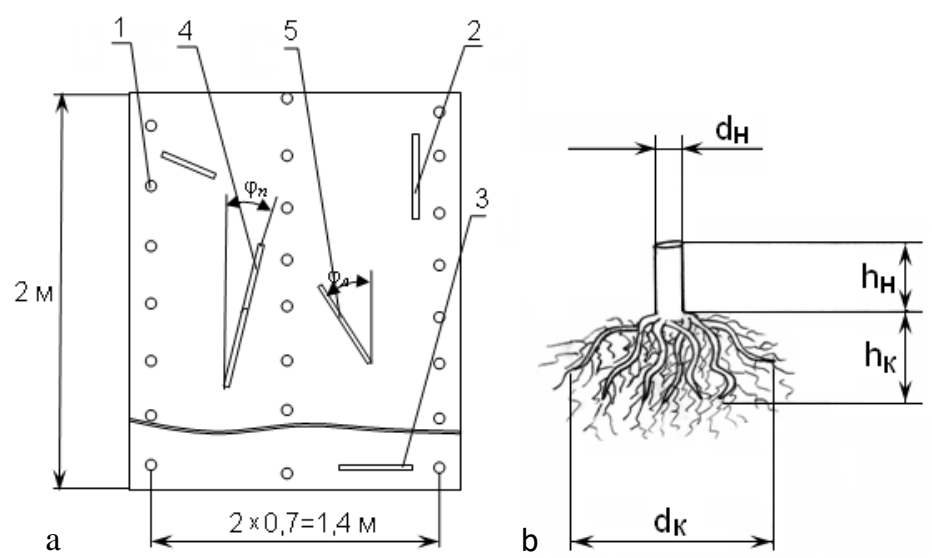

Fig. 2. Measurements scheme: a - plant residues; b - rhizomes; 1 - radical parts; 2 longitudinal stems; 3 - transverse stems; 4 - stems deviated right-ware; 5 - stems deviated left-ware; $\mathrm{d}_{\mathrm{K}}-$ rhizome diameter, $\mathrm{d}_{\mathrm{H}}-$ ground part diameter, $\mathrm{h}_{\mathrm{k}}-$ rhizome height; $\mathrm{h}_{\mathrm{g}}-$ ground part height.

Planning tests and processing the results obtained was carried out according to the existing techniques of field and engineering experiments [7, 8].

Measurement variability of the object studied was determined by variant rows and variant curves.

With the aim of achieving a variant number or curves there were measured the parameter chosen and distributed the measurements given by classes (not more 100 dimensions) [9-12].

For that there was found (table 1):

1. Most less and greater dimensions $X_{\max }, X_{\min }$;

2. The number of intervals (classes) $\mathrm{K}$ :

$K=(3,2) \lg n$

where $n$-measurement number.

$$
K=\frac{X_{\max }-X_{\min }}{\Delta} \text {. }
$$

3. The lower and the upper boundary of the 1-st class:

$X_{I}{ }^{H} \leq X \min ; X_{1}{ }^{B}=X_{I}+\Delta$.

4. Other classes were calculated similarly. 
5. The frequency ( $m$ - measurements number) was calculated in each class when evaluating it by absolute significance for number, as well as percentage respectively.

6. The intervals mids were determined:

$$
X_{i c}=\frac{X_{i}^{\mu}+X_{i}^{\beta}}{2} \text {. }
$$

Table 1. Variation series

\begin{tabular}{|c|c|c|c|c|c|c|}
\hline Classes & $1-\mathrm{st}$ & 2-nd & $3-d$ & $\ldots$ & $\mathrm{n}$ & Total \\
\hline Class boundaries & $X_{I^{H}} \ldots X_{I^{B}}$ & $X_{2}{ }^{H} \ldots X_{2}{ }^{B}$ & $X_{3^{H}} \ldots X_{3^{6}}$ & $\cdots$ & $X_{n}{ }^{H} \ldots X_{n}{ }^{B}$ & - \\
\hline $\begin{array}{l}\text { Mean values of class } \\
\text { boundaries }\end{array}$ & $X_{l c}$ & $X_{2 c}$ & $X_{3 c}$ & $\ldots$ & $X_{n c}$ & - \\
\hline $\begin{array}{l}\text { Frequency (measurement } \\
\text { number), } \mathrm{m}\end{array}$ & $m_{1}$ & $m_{2}$ & $m_{3}$ & $\ldots$ & $m_{n}$ & $\Sigma m_{i}$ \\
\hline $\mathrm{P}$ (percentage), \% & $p_{1}$ & $p_{2}$ & $p_{3}$ & $\ldots$ & $P_{n}$ & 100 \\
\hline
\end{tabular}

According to the variation series variational curves which are graphs were plotted along the abscissa which were deposited with measured values corresponding to the average value of the class boundary and along the ordinate axis, the frequencies ( $m$ or $p, \%)$ of measurements within each class.

Variational series and curves were compared by the arithmetic mean of $M_{c}$ and the standard deviation $\sigma$ (measurement dispersion):

$$
M_{c}=\frac{\sum m_{i} \cdot x_{i c}}{\sum m_{s}} ; \sigma=\sqrt{\frac{\sum\left(M_{c}-X_{c i}\right)^{2} \cdot m_{i}}{\sum m_{i}}} .
$$

Changes in size in most cases obey the law of normal distribution, it is known from probability theory that with a normal distribution of dimensional characteristics, $99,7 \%$ of the material amount is laid within $\left(M_{c} \pm 3 \cdot \sigma\right)$.

\section{Results and discussion}

Useful experimental studies of the weediness of the field by plant residues of thickstem crops were carried out on the experimental field of State Agrarian and Engineering University in Podilia.

Soil type - chernozem (black earth zone) ordinary, slightly humus. Background stubble after corn harvesting.

Processing the experimental data according to the method described above, a series of variation curves was obtained from which above given parameters were calculated.

The research results are as follows:

5.1. Results of the distribution of dimensional characteristics of rhizomes and ground parts.

5.1.1. Characteristics of the height and diameter of the rhizome (fig.3.).

Examining the research data found: $h_{\kappa \max }, h_{\kappa \min }, d_{\kappa \max }, d_{\kappa} \min$.

$h_{\max }=13 \mathrm{~cm}, h_{\min }=6 \mathrm{~cm}, d_{\max }=20 \mathrm{~cm}, d_{\min }=8,5 \mathrm{~cm}$. 
many times Rhizome height

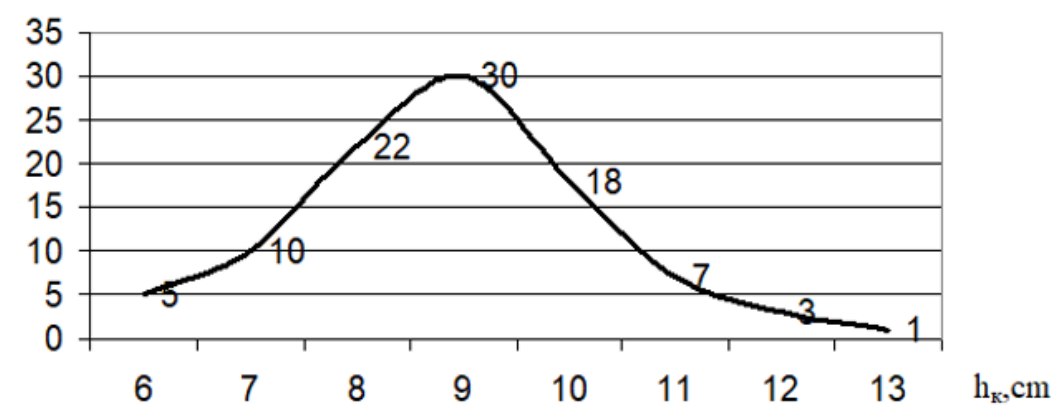

a)

many times

Rhizome diameter

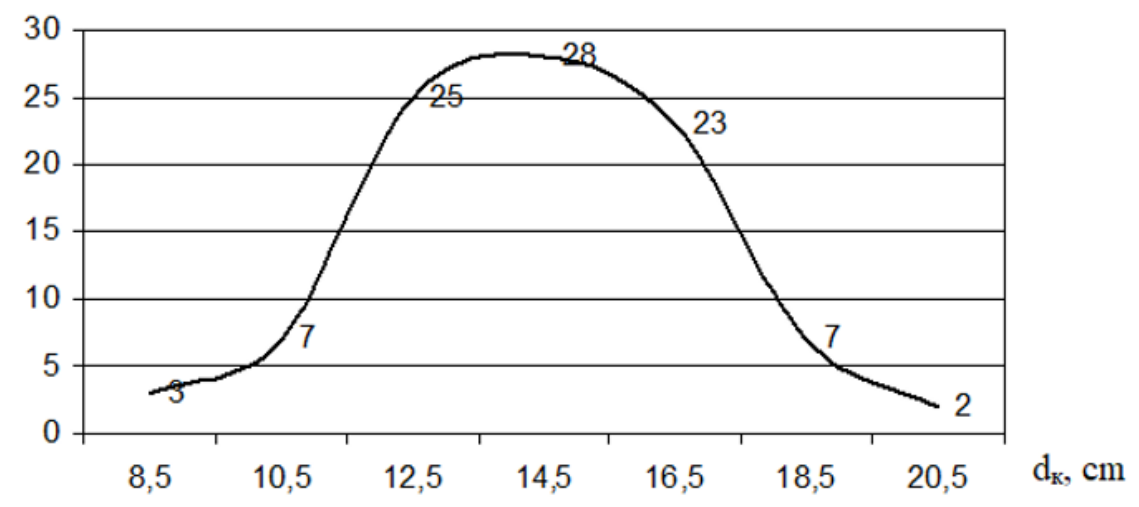

b)

Fig. 3. Research results: a) rhizome height $\left(\mathrm{M}_{\mathrm{c}}=8,9 \mathrm{~cm} ; \sigma=1,4 \mathrm{~cm}\right)$; b) rhizome diameter $\left(M_{c}=\right.$ $14,4 \mathrm{~cm} ; \sigma=2,5 \mathrm{~cm}$ )

5.1.2. Characteristic of the height and diameter of the ground part (fig.4.)

When examining research data there were found: $h_{\text {н.ч. } \max }, h_{\text {н.ч. } \min }, d_{\text {H.ч. } \max }, d_{\text {H.ч. } \min }$. $h_{\text {H.ч. } \max }=24 \mathrm{~cm}, h_{\text {H.ч. } \min }=6 \mathrm{~cm}, d_{\text {H.ч. } \max }=24 \mathrm{~mm}, d_{\text {H.ч. } \min }=11 \mathrm{~mm}$.

5.2. Results of distribution of dimensional characteristics of plant residues at interrows (fig.5.)

5.2.1. Characteristic of total number of plant residues

$x_{\text {max }}=12$ pieces, $x_{\text {min }}=0$. 
many times Ground part height

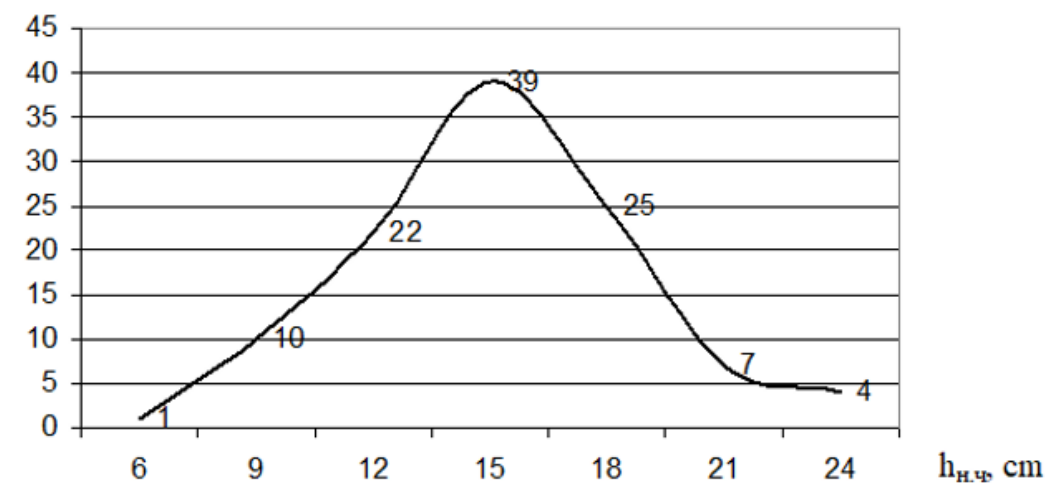

a)
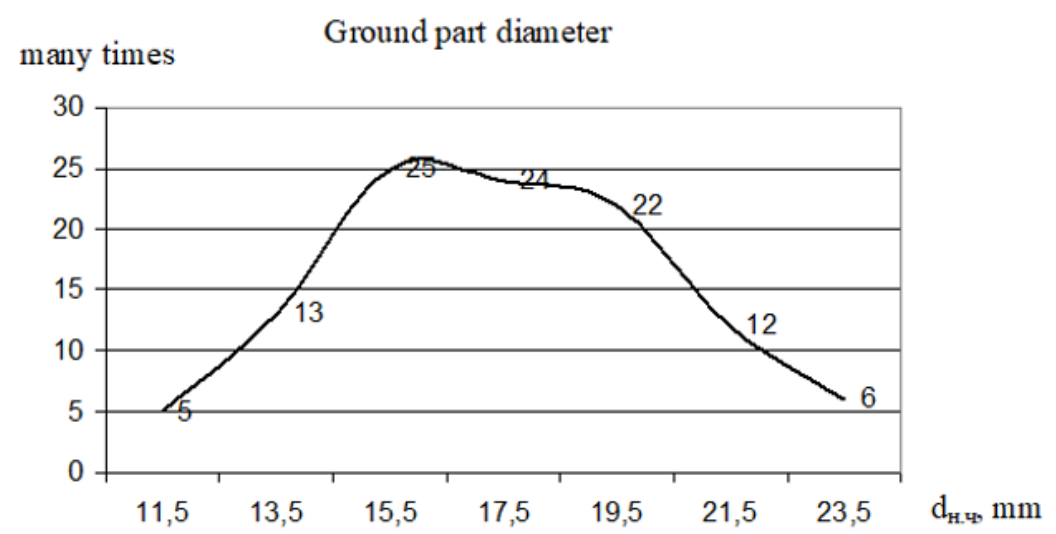

b)

Fig. 4. Research results: a) ground part height $\left(M_{c}=15,2 \mathrm{~cm} ; \sigma=3,7 \mathrm{~cm}\right)$;

b) ground part diameter $\left(M_{c}=17,5 \mathrm{~mm} ; \sigma=3,0 \mathrm{~mm}\right)$

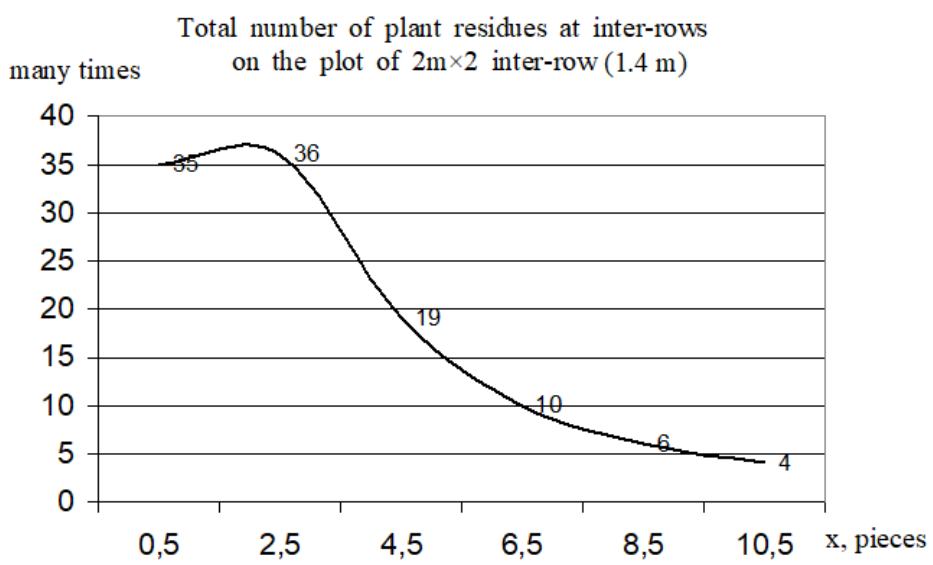

Fig. 5. Results of study of the total number of plant residues in the rows. Variation curve of the total number of plant residues ( $M_{c}=3,2$ pieces; $\sigma=2,5$ pieces) 


\subsubsection{Characteristic of plant residues length (fig.6.).}

The length of plant residues that remained between the rows and their diameter was determined both in total amount and separately: longitudinal (and also deviated by an angle of no more $\pm 40 \%$ ), and transverse ones (deviated more than $60 \%$ ) of the stem.

$\mathrm{X}_{\max }=155 \mathrm{~cm} ; \mathrm{X}_{\min }=24 \mathrm{~cm}$.

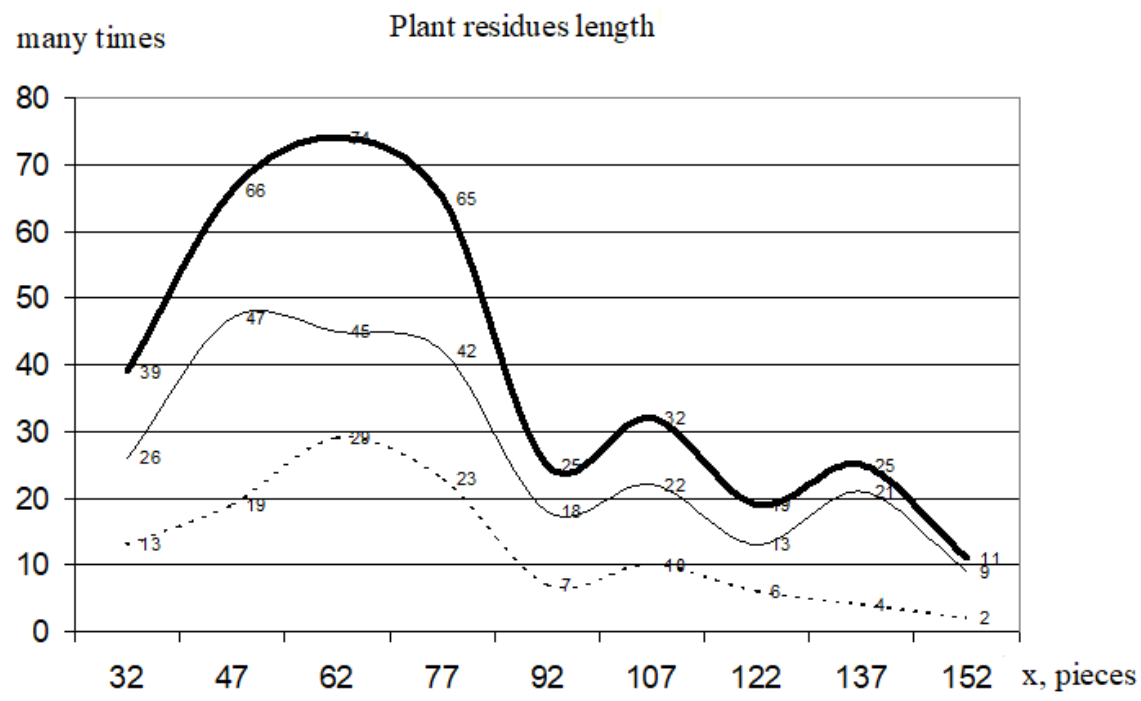

Fig. 6. Results of study of plant residues length at inter-rows: total number of stems-solid thick, longitudinal stems-solid thin, transverse stems-dotted.

As can be seen in Figure 6 measurements taken to the average parameter $92 \mathrm{~cm}$ are subjected to the law of normal distribution. When higher - the deviations are appeared. This is explained by the presence of whole stems of crops in the field that remained due to poor quality work of machinery during harvesting.

In this case the determination of mean arithmetic and mean square deviations is impractical:

5.2.3. Characteristic of plant residues diameter (fig.7.)

$\mathrm{X}_{\max }=25 \mathrm{~mm} ; \mathrm{X}_{\min }=5 \mathrm{~mm}$. 


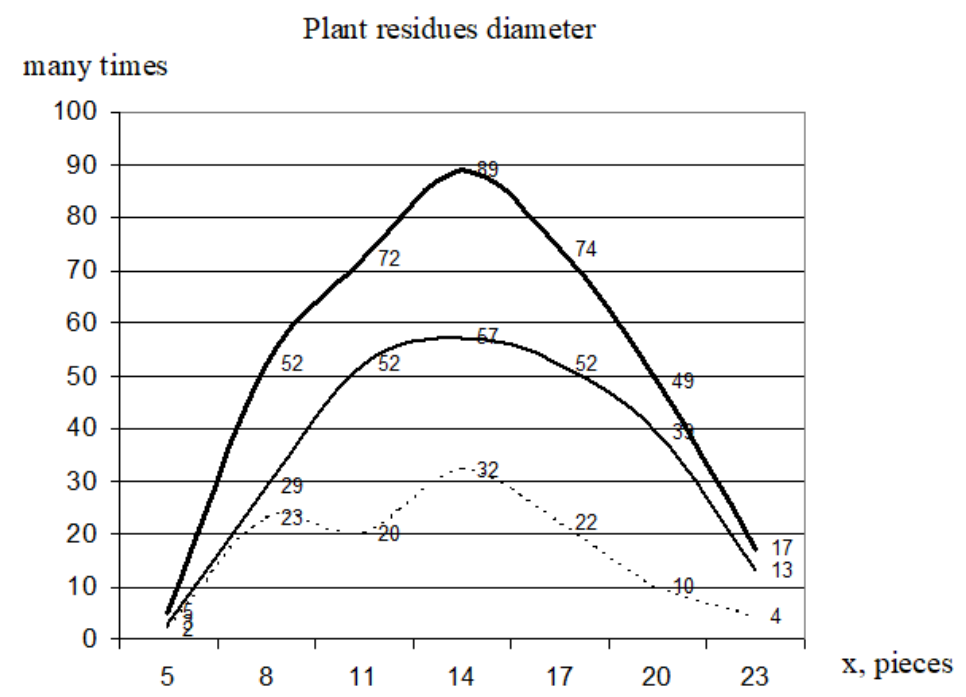

Fig. 7. Results of study of plant residues at inter-rows: total number of stems-complete thick, longitudinal stems-solid thin, transverse stems - dotted $\left(\mathrm{M}_{\mathrm{c}}=14,3 \mathrm{~mm} ; \sigma=4,33 \mathrm{~mm}\right)$

Experimental data of rhizomes showed that the bulk of the roots is at a depth of $8 \mathrm{~cm}$. So, the depth of milling when conducting useful research is chosen in the range from 2 to 8 $\mathrm{cm}$.

As a result of the research conducted on the state of the field weediness by rhizomes and their ground part the following was revealed:

- the variance or standard deviation of all measurements is quite significant that is significant variation of parameters (within $M=3 \pm \sigma$ );

- the medium-arithmetic development of height of the rooster (rhizome) $\mathrm{M}_{\mathrm{c}}=8,9 \mathrm{~cm}$ with with variation curve is visible that the basic part of the heights lies in the limits of 7,5 $-10 \mathrm{~cm}$. This indicates that for treatment (cultivation) of the rooting system considering the degree of crushing, it is enough to enhance the working body in $8 \ldots 9 \mathrm{~cm}$;

- average arithmetic deviation of the diameter of the rhizome $M_{c}=14,4 \mathrm{~cm}$, and the main part of measurements lies within $12,5 \ldots 18,5 \mathrm{~cm}$; therefore the required row cultivation width is at least $20 \mathrm{~cm}$;

- diameter of the ground part varies widely the main part of measurements is $15 \ldots 20$ $\mathrm{cm}$ and reaches a maximum of $24 \mathrm{~cm}$. This should be considered when choosing the method of grinding and the working body;

- the average value of the height of the ground part (cutting height) is $15,2 \mathrm{~cm}$ which meets the agrotechnical requirements of corn harvesting.

- analyzing the quantitative characteristics of the field surface, we can see that after corn harvesting there is still fairly significant amount of plant residues on the field and the value of the various parameters varies within fairly wide limits;

- analysis of the total amount of plant residues shows that only $16,2 \%$ of the plots (with an area of 2,8 $\mathrm{m}^{2}$ ) are clean, that is, they do not have plant residues in between rows. Their average number is 3,2 units, although in some areas their number reaches 10 or more;

- the average length of plant residues in between rows should be taken along the main curve (up to $92 \mathrm{~cm}$ ), which is similar to the normal distribution curve. 
It reaches a maximum in the interval from 47 to $77 \mathrm{~cm}$;

- when choosing the method of freeing the field from plant residues, whole stems should also be taken into account since they constitute about $25 \%$ of the total amount of plant residues in between the rows, arranged longitudinally and are mainly in the row zone;

- the average diameter of plant residues is $14,2 \mathrm{~mm}$ with a maximum value of $24 \mathrm{~mm}$., which has some similarity with the diameter of the ground part (measurements were made on the larger of the side of the stem);

Considering the obtained statistical quantitative data of debris and their quantitative characteristics:

- the presence of a large amount of crop residues both in a row and between the rows makes it difficult to cultivate the soil and worsen the further use of the field which requires carrying out operations to free the fields from coarse plant residues, more over, given the fibrous structure of corn stalks, it can be concluded that for grinding the corn crop residues it is necessary to use working bodies that cut rather than break the stems, provide a sufficient degree of grinding, good sealing and mixing with the soil. Milling tools are best suited for this;

On the basis of studies of the state of contamination a method has been developed for cultivation a field clogged with plant residues of thick-stem crops and shredder for its implementation [13-15].

The novelty of technical decisions was confirmed by patents of Ukrainian invention [16-22].

\section{Conclusions}

Corn biomass is effectively used in the energy sector, the non-cereal part of corn is used in the form of solid fuel in the form of granules, briquettes and bales because it has better fuel characteristics than straw grains of corn. In addition the biomass of corn has good energy indicators relative to other types of energy carriers of plant origin which positively characterizes this raw material for use as an energy source.

Monoculture corn cultivation provides a high-yield of grain per unit area, enhances soil erosion control, requires the creation of appropriate hybrids with a stable yield and resistance to pests and diseases according to the growing zone which allows to use part of the grain yield and foliage-stem mass for energy needs.

In the system of autumn tillage for maize crops in a monoculture great importance is given to the thorough grinding of crop stalk residues. That is why the study of the state of weediness of the field after harvesting the corn remains quite relevant.

\section{References}

1. M.M. Korchak Study of the nature of the field weediness with leafy and root residues after harvesting corn. Collection of scientific papers of the State Agrarian and Engineering University in Podilia. Issue 15. Kamyanets-Podilskyi. p. 498 - 504. (2007)

2. P.I. Boyko Corn (Maize) in intensive crop rotation. Kyiv: Urozhay. 144 p. (1990)

3. T. Hutsol, S. Yermakov, Ju. Firman, V. Duganets, A. Bodnar Analysis of technical solutions of planting machines, which can be used in planting energy willow. Renewable Energy Sources: Engineering, Technology, Innovation. p.99-111 (2018)

4. I.S. Gogulyan Maize in crop rotations, 2-nd edition processed and supplemented by Kyiv: Urozhay. 104 pages. (1977) 
5. I.S. Godulyan Rational crop rotations - basis of high yield. Dnepropetrovsk: Promin', 160 p. (1972)

6. S.Yermakov, T. Hutsol, S. Slobodian, S. Komarnitskyi, M. Tysh Possibility of using automation tools for planting of the energy willow cuttings. Renewable Energy Sources: Engineering, Technology, Innovation. p. 419-429. (2018)

7. V.Yu. Ilchenko, Yu.P. Nagirny Machine use in agriculture Kyiv: Urozhay. 384 p. (1996)

8. G.E. Lystopad, G.K. Demidov, B.D. Zonov Agricultural and land reclamation machines Moskow: Kolos, 752 p. (1976)

9. V. Sheichenko, I. Marynchenko, I. Dudnikov, M. Korchak. Development of technology for the hemp stalks preparation. Independent Journal of Management and Production. State agrarian and engineering university in Podilia. V. 10, № 7. p. 687 701 (ISSN: 2236-269X)

10. S. Yermakov, K. Mudryk, T. Hutsol, K. Dziedzic, L. Mykhailova The analysis of stochastic processes in unloadingthe energywillow cuttings from the hopper. Environment. Technology. Resources. Rezekne, Latvia. Proceedings of the 12th International Scientific and Practical Conference. Volume III. p. 249-252 (2019)

11. S. Yermakov, T. Hutsol, O. Ovcharuk, I. Kolosiuk Mathematic simulation of cutting unloading from the bunker. Independent journal of management $\&$ amp; production (IJM\&P). p. 758-777 (2019)

12. S. Yermakov, T. Hutsol Features of the heterogeneous rod-like materials outflow. Technological and methodological aspects of agri-food engineering in young scientist research. Krakow, 2018, pp. 55-68 (2018)

13. M.M. Korchak Development of a combined method and a grinder for soil littered by plant residues. Visnyk of Lvivsky national agrarian university: Agrarian and engineering research. Lviv national agrarian university. № 13, volume 1. p. 155-163. (2009)

14. M.M. Korchak Substantiation of the technological functional model of the method of tillage after harvesting rough-stem crops. Collection of scientific and research works. Podilsky Agrarian and Engineering University. - Kamyanets-Podilsky, 2016. Edition 24, part 2. - $165-174$ pages.

15. M.M. Korchak Analysis of exploratory experimental studies of plant-residues grinder of rough-stem crops. Kamyanets-Podilsky Visnyk: agriculture, machinery, ecinimics. Edition 25. Kamyanets-Podilsky, p. 99 - 114. (2017)

16. Cutter-grinder of root-leaf and stem residues. Patent 29342, Ukraine, MPK A $01 \mathrm{~V}$ 33/00. № u200710230; application 14.09.2007; published 10.01.2008, Bulletin № 1 . (2008).

17. Grinder of root and leaf-stem residues. Patent 31514, Ukraine, MPK A 01 V 33/00. № u200714212; application 18.12.2007; published 10.04.2008, Bulletin № 7. (2008).

18. Combined cultivator-grinder. Patent 33829, Ukraine, MPK A 01 V 33/00. № u200803382; application 17.03.2008; published 10.07.2008, Bulletin № 13. (2008).

19. Combined cutter cultivator-grinder of plant rests of rough-stem crops. Patent 33819 , Ukraine, MPK A 01 V 33/00. № u200803323; application 17.03.2008; published 10.07.2008, Bulletin № 13. (2008).

20. The way of releasing field from plant residues of releasing field from plant residues of rough-stem crops. Patent 90538, Ukraine, MPK A 01 V 33/00. № a2008 04264; application 04.04.2008; published 11.05.2010, Bulletin № 9. (2010). 
21. Combined grinder of plant residues of rough-stem crops. Patent 90535, Ukraine, MPK A 01 V 49/02 (2006.01). № a2008 03070; application 11.03.2008; published 11.05.2010, Bulletin № 9. (2010).

22. Antierosive ecological device. Patent 93012, Ukraine, MPK (2014.01) A01 B33/00. № u2014 04543; application 28.04.2014; published 10.09.2014, Bulletin №17. (2014). 